\title{
A STUDY OF ASSESSMENT OF OCCUPATIONAL NOISE INDUCED HEARING LOSS IN INDUSTRIAL WORKERS
}

\author{
Praveen Kumar', Kavyashree R2, Chandni R. Pillai ${ }^{3}$, Sachin S. Nair ${ }^{4}$
}

1 Professor, Department of ENT-Head and Neck Surgery, Raja Rajeswari Medical College and Hospital, Bangalore, Karnataka, India. ${ }^{2}$ Senior Resident, Department of ENT-Head and Neck Surgery, Raja Rajeswari Medical College and Hospital, Bangalore, Karnataka, India.

3Postgraduate Student, Department of ENT-Head and Neck Surgery, Raja Rajeswari Medical College and Hospital, Bangalore, Karnataka, India.

${ }^{4}$ Postgraduate Student, Department of ENT-Head and Neck Surgery, Raja Rajeswari Medical College and Hospital, Bangalore, Karnataka, India.

\begin{tabular}{l}
\hline ABSTRACT \\
BACKGROUND \\
Noise is the insidious of all industrial pollutants, involving every industry and causing severe hearing loss in every country in the \\
world. Occupational hearing loss includes acoustic traumatic injury and noise induced hearing loss, and can be partial or complete \\
hearing loss in one or both ears as a result of one's employment. Exposure to excessive noise is the major avoidable cause of \\
permanent hearing impairment. \\
In this study, we studied noise induced hearing loss in industrial workers in and around Rajarajeswari Medical College and Hospital \\
and we compared the effect of noise in two different industries.
\end{tabular}

\section{METHODS}

Data for the study was collected from industrial workers who were taken to the department of ENT, Head and Neck Surgery at Rajarajeswari Medical College and Hospital, Bangalore. The period of the study was from $1^{\text {st }}$ October 2014 to $2^{\text {nd }}$ March 2016 . An informed written consent was taken from the patient and cases meeting the selection criteria were included in the study.

Pure tone audiometry was calculated.

Monoaural and Binaural hearing impairment was calculated.

\section{RESULTS}

We studied a total of 200 cases, 100 workers from each industry with 74 having hearing loss during a period of one and a half year.

\section{CONCLUSION}

As adequate sample size could not be ensured, the results of this study could not be generalized but comparable with similar types of studies only. A significant association was observed between the hearing loss and duration of exposure in both the ears among workers exposed to $85 \mathrm{~dB}$ of noise in Group 1 and $75 \mathrm{~dB}$ of noise in Group 2.

Regarding the pattern of hearing protector use, there were many assumptions and limitations.

\section{KEY WORDS}

Noise Induced Hearing Loss.

HOW TO CITE THIS ARTICLE: Kumar P, Kavyashree R, Pillai CR, et al. A study of assessment of occupational noise induced hearing loss in industrial workers. J. Evolution Med. Dent. Sci. 2018;7(47):5128-5133, DOI: 10.14260/jemds/2018/1138

\section{BACKGROUND}

"This evolution of music is comparable to the multiplication of machines, which everywhere collaborate with man. Not only in the noisy atmosphere of the great cities, but even in the country, which until yesterday was normally silent. Today, the machine has created such a variety and contention of noises that pure sound in its slightness and monotony no longer provokes emotion." -Luigi Russolo, Milan, March 11th, 1913.

'Financial or Other Competing Interest': None.

Submission 26-01-2018, Peer Review 20-09-2018,

Acceptance 27-09-2018, Published 19-11-2018.

Corresponding Author:

Dr. Praveen Kumar,

No. 5/6, Anugraha,

Near St. Peter School, Nagadevanahalli,

Bangalore South-560056,

Karnataka, India.

E-mail: praveendrkumar@gmail.com

DOI: $10.14260 /$ jemds $/ 2018 / 1138$

\section{(c) $(1) \ominus$}

\section{Historical Background}

Acoustics is a multi-disciplinary translational science that studies mechanical waves propagating in physical media (i.e., gases, liquids and solids) in form of sound, ultrasound and infrasound.

The word acoustics takes root from the Greek word akoustos meaning 'audible' although modern acoustics also includes inaudible mechanical vibrations, infrasound and ultrasound. 1

In $16^{\text {th }}$ century, Galileo Galilei (1564- 1642) wrote "Waves are produced by the vibrations of a sonorous body, which propagates through the air, bringing to the tympanum of the ear a stimulus which the mind perceives as sound".2

In 19th century, the Italian anatomist Aslfonso Corti (1822-1876) conducted microscopic research on at least 200 human and animal cochleae and discovered the sensory structures of the mammalian auditory system which was later named after him as the organ of Corti. ${ }^{3}$

Hermann Von Helmholtz (1821-1894) published his theory of resonance which hypothesized that the inner ear acts 
as a combination of independent resonators similar to tuning forks or a piano string. ${ }^{3}$

Georg Von Bekesy (1899-1972) published his first paper on the pattern of vibration inside inner ear, in 1928. ${ }^{4}$ Bekesy developed a method to assess biophysical properties of the cochlear structures in human cadaver temporal bones, using strobe photography. Bekesy implemented a mechanical replica of the human cochlea to simulate the sound-induced vibrations. The results confirmed the key concept of frequency dispersion by the organ of Corti (so called 'tonotopy'), as was also predicted by Helmholtz resonators. ${ }^{5}$

Noise is the insidious of all industrial pollutants, involving every industry and causing severe hearing loss in every country in the world. Occupational hearing loss includes acoustic traumatic injury and Noise induced hearing loss (NIHL), and can be partial or complete hearing loss in one or both ears as the result of ones employment. Exposure to excessive noise is the major avoidable cause of permanent hearing impairment. ${ }^{6}$ Worldwide, $16 \%$ of the disabling hearing loss in adults is attributed to occupational noise, ranging from 7 to $21 \%$ in the various subregions. ${ }^{6}$

NIHL is generally used to denote the cumulative, permanent loss of hearing that develops gradually after months or years of exposure to high levels of noise. It has long been recognized as a problem in occupations associated with prominent noise. NIHL is the second most common form of acquired hearing loss after age related loss (presbycusis), with studies showing the people who are exposed to noise levels higher than $85 \mathrm{~dB}$ suffered from NIHL. ${ }^{7}$

A typical NIHL is of a sensory neural type involving injury to the inner ear. Noise induced hearing loss is bilateral and symmetrical, usually affecting the higher frequencies $(3 \mathrm{k}, 4 \mathrm{k}$ or $6 \mathrm{k} \mathrm{Hz})$ and the spreading to lower frequencies $(0.5 \mathrm{k}, 1 \mathrm{k}, 2 \mathrm{k}$ $\mathrm{Hz}) .^{8}$ Impairment of hearing at high frequencies will initially cause a loss of clarity in perceived speech and then interfere with daily activities as hearing loss progresses. ${ }^{8}$

Other major health effects are lack of concentration, irritation, fatigue, headache, sleep disturbances, etc. The major industries responsible for excessive noise and exposing workers to hazardous levels of noise are automobile industries, telecom industries etc.

Earmuffs, ear plugs, and ear canal caps are the main types of hearing protectors. Awareness should be created among workers about the harmful effects of noise on hearing.

The Major Industries responsible for excessive noise and exposing workers to hazardous levels of noise are automobile industries, telecom industries etc. hearing protectors should be used when engineering controls and work practise are not feasible for reducing noise exposure to safe levels ${ }^{9}$

Raja S, Ganguly G. (1983) ${ }^{10}$ study was conducted in heavy engineering industry, which included machines shop and press divisions. The sound levels to which exposed ranged from 83 to $116 \mathrm{dBA}$. Hearing impairment was progressive in all the study groups Bhattacharya SK, Saiyed HN, Roy A, Chatterjee SK (1983) ${ }^{11}$ In a textile mill weavers' study, the sound levels were around 102-104 dBA and the hearing acuity of the textile weavers

was found to be poor. NIHL at $4000 \mathrm{~Hz}$ was as high as $30 \mathrm{~dB}$ in the age range $2540 \mathrm{~dB}$ in the age range 3034 years and $45 \mathrm{~dB}$ in the age range 3539 years Bhattacharya SK, Tripathi SR,
Kashyap S (1990) ${ }^{12}$ conducted a study in a drug and pharmaceutical company where the noise levels were 100105 dBA. Significant NIHL was found in the workers Kumar A, Mathur NN, Varghese M, Mohan D, Singh JK, Mahajan P(2005) In their cross sectional study, the hearing status of tractor driving farmers (TDFs) was compared with that of non TDFs. All participants were interviewed for details of $w$ ork routine and noise exposures. Audiogram analysis showed higher prevalence of abnormalities in TDFs. TDFs more often had a higher frequency of hearing loss when compared with non TDFs $^{13}$ Reilly, Mary Jo MS; Rosenman, Kenneth D. MD; Kalinowski, Douglas J. MS conducted the study on Occupational Noise-Induced Hearing Loss Surveillance in Michigan. Individuals with occupational NIHL were reported to the Michigan Department of Consumer and Industry Services (MDCIS). During the interview workers exposed to the noise level more than $85 \mathrm{dBA}$ was known ${ }^{14} \mathrm{D}$ I McBride ,S Willims conducted study on Audiometric notch as a sign of noise induced classic sign of noise induced hearing loss (NIHL), the audiometric notch. Prevalent cases of NIHL were identified by the presence of a notch in either ear ${ }^{15}$

\section{Objectives}

1. To assess occupational noise induced hearing loss in industrial workers in and around Rajarajeswari Medical College and Hospital.

2. To compare the effect of noise on two different industries.

\section{MATERIALS AND METHODS}

A Cross - sectional Comparative study of Assessment of Occupational Noise induced hearing loss in industrial workers was conducted on the employees of "Bombay Rayon Fashions" and "Vinpack" (Indian Private Limited) in the Department of ENT, Rajarajeswari Medical College and Hospital, Kambipur, Mysore road, Bangalore from October 2014 to March 2016.

The study was carried out to find out the prevalence of Noise induced hearing loss in Industrial workers in and around Rajarajeswari Medical College and Hospital.

Each patient was examined comprising detailed history and physical examination.

Pure Tone Audiometry was done to know the degree of hearing loss and hence, the Hearing Handicap.

PTA

- $\quad<25 \mathrm{~dB}$ HL considered as Normal.

- $\quad>25 \mathrm{~dB}$ HL considered as hearing loss.

\section{Hearing handicap}

- 0 was considered as no handicap.

- 1-20 was considered as mild handicap.

- 21-40 was considered as moderate handicap.

- $>40$ was considered as severe handicap.

\section{Statistical Methods}

Descriptive and inferential statistical analysis has been carried out in the present study. Results on continuous measurements are presented on Mean \pm SD (Min-Max) and results on categorical measurements are presented in Number (\%). Significance is assessed at $5 \%$ level of significance.

Student $t$ test (Two tailed, independent) has been used to find the significance of study parameters on continuous scale 
between two groups (Inter group analysis) on metric parameters.

Chi-square/ Fisher Exact test has been used to find the significance of study parameters on categorical scale between two or more groups.

\section{Significant Figures}

+ Suggestive significance ( $\mathrm{P}$ value: $0.05<\mathrm{P}<0.10$ )

* Moderately significant (P value: $0.01<\mathrm{P} \leq 0.05$ )

** Strongly significant (P value: $\mathrm{P} \leq 0.01$ )

\section{Statistical Software}

The Statistical software namely SAS 9.2, SPSS 15.0, were used for the analysis of the data and Microsoft word and Excel have been used to generate graphs, tables etc.

\section{METHODOLOGY}

The present study "A Study of Assessment of Occupational Noise induced hearing loss in industrial workers" was conducted in the department of ENT, Rajarajeswari Medical College and Hospital. Two hundred industrial workers of age group between 20 yrs. -50 yrs. and both genders were selected.

\section{This is a Cross-Sectional Comparative Study}

The two industries selected were Textile industry (Bombay Rayon Fashions) in sewing, edge seaming and pressing section and Biscuit factory (Vinpack) in sheeting, doughing and cutting section

\section{Period of Study}

1 and a half years.

\section{Sample Size}

200 industrial workers and high-risk patients.

The workers age group varied between 20-50 years.

Noise level at both work-places were measured with the help of Sound Level Meter, by the standard procedure given by Indian Standard Institute.

The noise level in the Textile industry was found to be around $85 \mathrm{~dB}$ with continuous type of noise and the noise level in Biscuit factory was found to be around $75 \mathrm{~dB}$ intermittent type of noise.

A proforma was filled for each patient documenting age, gender, address and clinical information. Other medical history like diabetes mellitus, hypertension and tuberculosis, etc. were noted.

All the workers were studied for the presence of NIHL. Audiologist performed a Screening PTA -Air conduction thresholds on all workers in our hospital, in a relatively free room. 3N3 Elkon EDA Micro- diagnostic Audiometer was used for the same.

Audiogram of NIHL shows air and bone conduction, both reduced bilaterally with notch at $4 \mathrm{KHz}$. Typical audiogram of NIHL along with exclusion of all other ascertainable causes of hearing loss confirmed diagnosis of NIHL.

The screening test was performed keeping the level constant at $25 \mathrm{~dB}$ at various frequencies.
Calculation of Monaural and Binaural Hearing Impairment

Monaural and binaural hearing impairment is expressed in terms of percentage by using threshold average of frequencies 1000, 2000, 3000 and $4000 \mathrm{~Hz}$. Hearing impairment was defined as a threshold average greater than $25 \mathrm{~dB}$ hearing level.

\section{RESULTS}

\begin{tabular}{|c|c|c|c|}
\hline Age in Years & Group I & Group II & Total \\
\hline $20-30$ & $27(27 \%)$ & $40(40 \%)$ & $67(33.5 \%)$ \\
\hline $31-40$ & $41(41 \%)$ & $27(27 \%)$ & $68(34 \%)$ \\
\hline $41-50$ & $32(32 \%)$ & $33(33 \%)$ & $65(32.5 \%)$ \\
\hline Total & $100(100 \%)$ & $100(100 \%)$ & $200(100 \%)$ \\
\hline Mean \pm SD & $36.17 \pm 7.40$ & $35.14 \pm 8.50$ & $35.66 \pm 7.96$ \\
\hline \multicolumn{4}{|c|}{ Table 2. Age Distribution of Patients Studied } \\
\hline
\end{tabular}

Samples are age matched with $\mathrm{P}=0.362$.

In Our study, we found that majority of workers, $41(41 \%)$ belonged to the age group between 31 yrs. - 40 yrs. in Group I; $40(40 \%)$ workers belonged to the age group between $20 \mathrm{yrs}$. -30 yrs. in Group 2.

\begin{tabular}{|c|c|c|c|}
\hline Gender & Group I & Group II & Total \\
\hline Female & $47(47 \%)$ & $44(44 \%)$ & $91(45.5 \%)$ \\
\hline Male & $53(53 \%)$ & $56(56 \%)$ & $109(54.5 \%)$ \\
\hline Total & $\mathbf{1 0 0 ( 1 0 0 \% )}$ & $\mathbf{1 0 0 ( 1 0 0 \% )}$ & $\mathbf{2 0 0 ( 1 0 0 \% )}$ \\
\hline \multicolumn{3}{|c|}{ Table 3. Gender Distribution of Patients Studied. } \\
Samples are Gender Matched with P=0.670 \\
\hline
\end{tabular}

In Our study, majority of workers were found to be Males in both Group I and Group II; 53\% and 56\% respectively.

Table 4: Duration of Employment in two groups of patients studied. $\mathrm{P}=0.143$, Not significant, Student $t$ test.

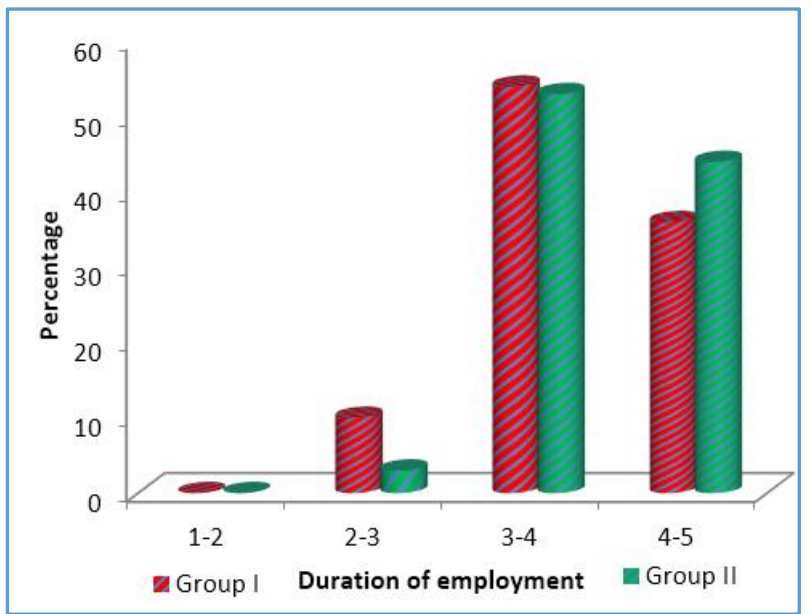

In Our study, majority of the workers were found with the duration of employment between 3 - 4 yrs.; 54\% and 53\% respectively.

Table 5: Hours of Working in two groups of patients studied. $\mathrm{P}<0.001^{* *}$, significant, chi-Square test. 


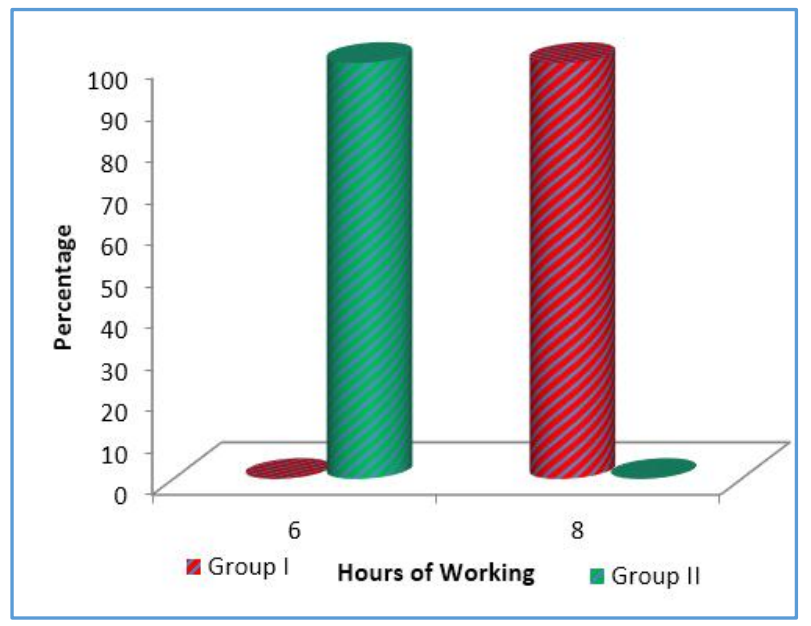

Figure 9. In Our study, Group I workers were found to be exposed for 8 hours; Group II workers were found to be exposed for 6 hours.

Table 6: Usage of Ear Plugs. $\mathrm{P}<0.001^{* *}$, Significant, ChiSquare test.

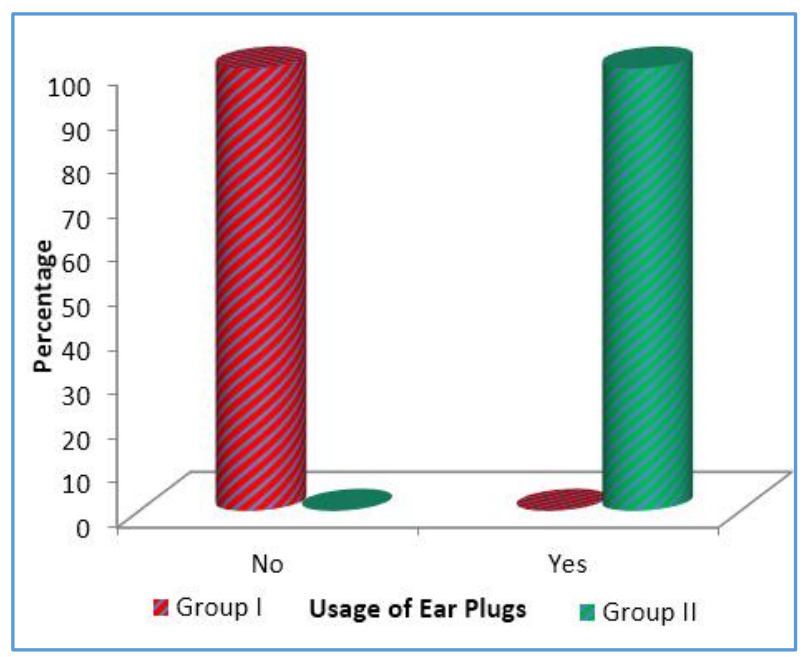

In our study, Group I workers were not using Ear Plugs; Group II workers were using Ear Plugs.

\begin{tabular}{|c|c|c|c|c|}
\hline PTA & $\begin{array}{l}\text { Group I } \\
(\mathrm{n}=100)\end{array}$ & $\begin{array}{l}\text { Group II } \\
(n=100)\end{array}$ & $\begin{array}{c}\text { Total } \\
(\mathrm{n}=\mathbf{2 0 0})\end{array}$ & $P$ value \\
\hline \multicolumn{4}{|c|}{ Right } & \\
\hline - $\quad<25$ & $46(46 \%)$ & $80(80 \%)$ & $\begin{array}{c}126 \\
(63 \%)\end{array}$ & \multirow{3}{*}{$<0.001^{* *}$} \\
\hline $26-50$ & $53(53 \%)$ & $19(19 \%)$ & $72(36 \%)$ & \\
\hline$>50$ & $1(1 \%)$ & $1(1 \%)$ & $2(1 \%)$ & \\
\hline \multicolumn{4}{|c|}{ Left } & \multirow{4}{*}{$<0.001^{* *}$} \\
\hline - $\quad<25$ & $48(48 \%)$ & $80(80 \%)$ & $\begin{array}{c}128 \\
(64 \%)\end{array}$ & \\
\hline - $26-50$ & $50(50 \%)$ & $15(15 \%)$ & $\begin{array}{c}65 \\
(32.5 \%)\end{array}$ & \\
\hline - $\quad>50$ & $2(2 \%)$ & $5(5 \%)$ & $7(3.5 \%)$ & \\
\hline \multicolumn{5}{|c|}{$\begin{array}{c}\text { Table 7. PTA Distribution: Comparison in Two Groups of } \\
\text { Patients Studied }\end{array}$} \\
\hline
\end{tabular}

Chi-Square test/Fisher Exact test.

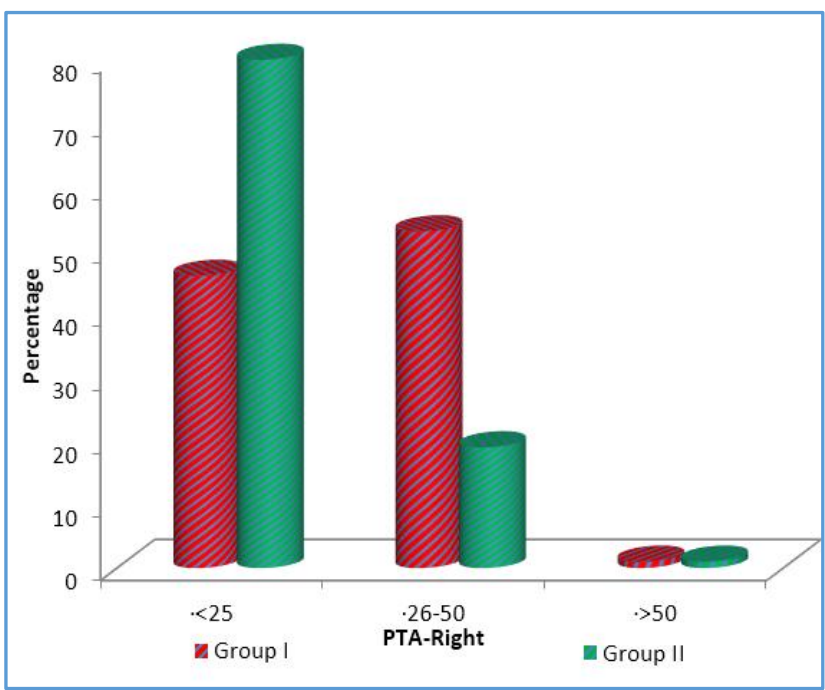

Figure 11

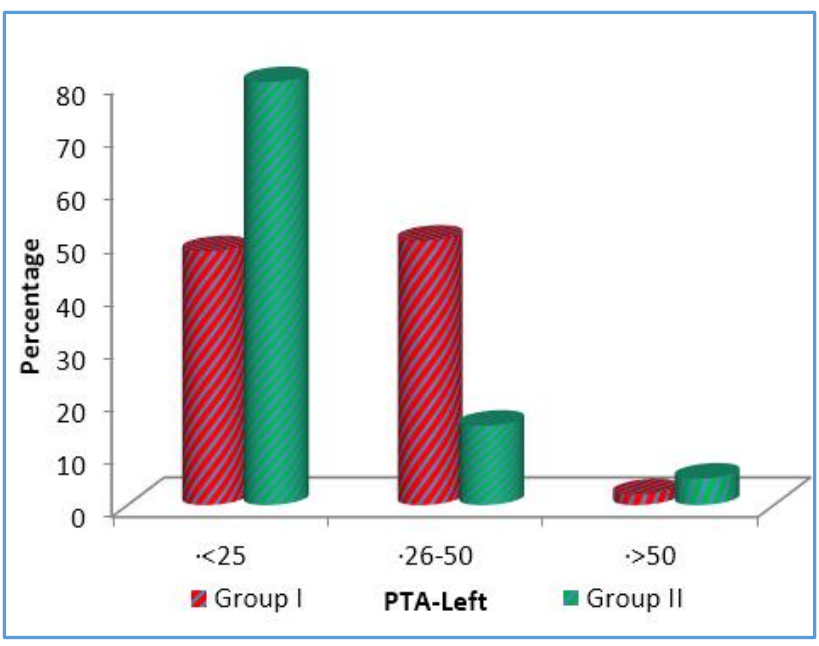

Figure 12

- In Our study: 46 workers had $<25 \mathrm{~dB}$ hl, 53 workers had 26-50 dB hl, 1 worker had $>50 \mathrm{~dB}$ hl on Right ear in Group I. 80 workers had $<25 \mathrm{~dB}$ hl, $26-50 \mathrm{~dB}$ hl in 19 workers, $>50 \mathrm{~dB}$ hl in 1 worker on Right ear Group II.

- $\quad 48$ workers had $<25 \mathrm{~dB} \mathrm{hl}, 50$ workers had 26-50 dB hl, 2 workers had $>50 \mathrm{~dB}$ hl on Left ear in Group I.

- 80 workers had <25 dB hl, 15 workers had 26-50 dB hl, 5 workers had $>50 \mathrm{~dB}$ hl on Left ear in Group II.

\begin{tabular}{|c|c|c|c|c|}
\hline PTA & Group I & Group II & Total & P value \\
\hline Right & $\begin{array}{c}27.49 \pm \\
12.47\end{array}$ & $\begin{array}{c}20.48 \\
\pm 13.43\end{array}$ & $\begin{array}{c}23.99 \pm \\
13.40\end{array}$ & $<0.001^{* *}$ \\
\hline Left & $\begin{array}{c}27.13 \pm \\
10.18\end{array}$ & $\begin{array}{c}21.99 \pm \\
12.95\end{array}$ & $\begin{array}{c}24.56 \pm \\
11.90\end{array}$ & $0.002^{* *}$ \\
\hline & & $\begin{array}{l}\text { fPTA in } \\
\text { Studied }\end{array}$ & & \\
\hline
\end{tabular}

Student $t$ test.

\begin{tabular}{|c|c|c|c|c|}
\hline $\begin{array}{c}\text { Percentage of } \\
\text { Hearing loss }\end{array}$ & $\begin{array}{l}\text { Group I } \\
(n=100)\end{array}$ & $\begin{array}{l}\text { Group II } \\
(n=100)\end{array}$ & $\begin{array}{c}\text { Total } \\
(n=200)\end{array}$ & $P$ value \\
\hline \multicolumn{4}{|c|}{ Right } & \\
\hline 0 & $46(46 \%)$ & $80(80 \%)$ & $126(63 \%)$ & \multirow{5}{*}{$<0.001^{* *}$} \\
\hline - $1-20$ & $32(32 \%)$ & $7(7 \%)$ & $39(19.5 \%)$ & \\
\hline $21-40$ & $21(21 \%)$ & $12(12 \%)$ & $33(16.5 \%)$ & \\
\hline $41-60$ & $1(1 \%)$ & $1(1 \%)$ & $2(1 \%)$ & \\
\hline$>60$ & $0(0 \%)$ & $0(0 \%)$ & $0(0 \%)$ & \\
\hline
\end{tabular}




\begin{tabular}{|c|c|c|c|c|c|}
\hline \multicolumn{5}{|c|}{ Left } & \multirow{6}{*}{0.350} \\
\hline & 0 & $48(48 \%)$ & $80(80 \%)$ & $128(64 \%)$ & \\
\hline & $1-20$ & $34(34 \%)$ & $6(6 \%)$ & $40(20 \%)$ & \\
\hline & $21-40$ & $16(16 \%)$ & $9(9 \%)$ & $25(12.5 \%)$ & \\
\hline & $41-60$ & $2(0 \%)$ & $5(5 \%)$ & $7(3.5 \%)$ & \\
\hline & $>60$ & $0(0 \%)$ & $0(0 \%)$ & $0(0 \%)$ & \\
\hline
\end{tabular}

Chi-Square test/Fisher Exact test.

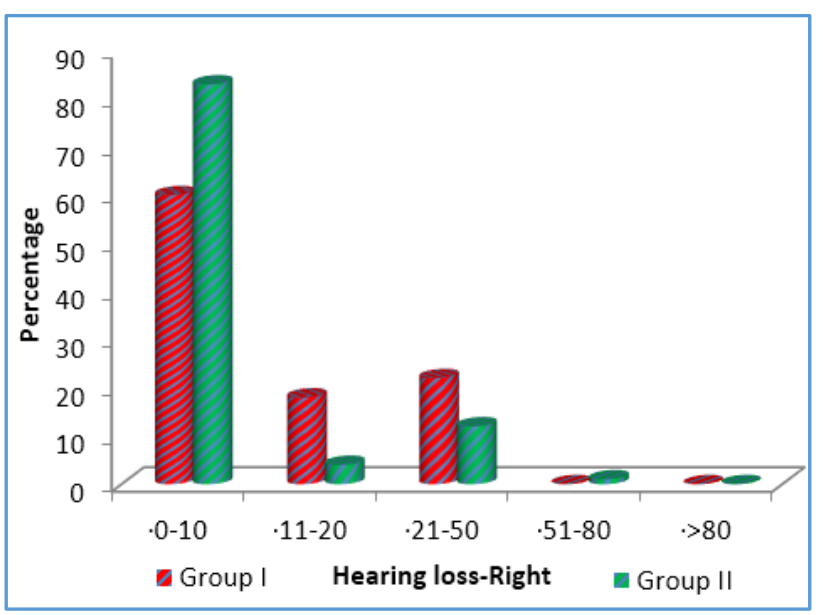

Figure 14

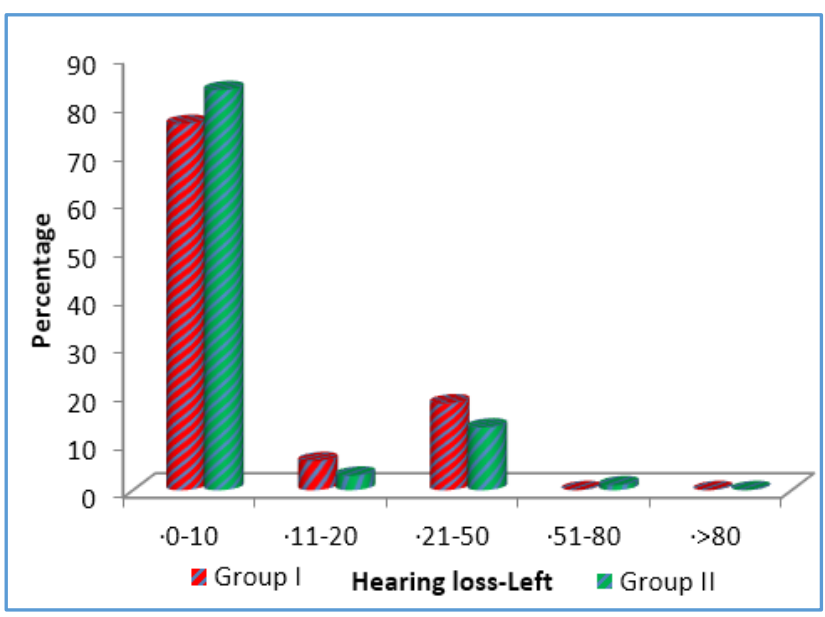

Figure 15

In Our study, we found that in Group I workers, Percentage of hearing loss was more in Right ear than Left ear.

In Group II workers, Percentage of hearing loss was more in Right ear than Left ear.

\begin{tabular}{|c|c|c|c|c|}
\hline $\begin{array}{l}\text { Percentage of } \\
\text { Hearing loss }\end{array}$ & Group I & Group II & Total & $P$ value \\
\hline Right & $\begin{array}{l}9.60 \pm \\
10.97\end{array}$ & $\begin{array}{c}5.12 \pm \\
5.12\end{array}$ & $\begin{array}{l}7.36 \pm \\
11.51\end{array}$ & $0.006^{* *}$ \\
\hline Left & $\begin{array}{l}7.70 \pm \\
10.25\end{array}$ & $\begin{array}{l}5.73 \pm \\
13.20\end{array}$ & $\begin{array}{l}6.72 \pm \\
11.87\end{array}$ & 0.243 \\
\hline Table 10. Co & $\begin{array}{l}\text { arison } \\
\text { o Grou }\end{array}$ & $\begin{array}{l}\text { Percen } \\
\text { of Patie }\end{array}$ & $\begin{array}{l}\text { e of Hec } \\
\text { Studie }\end{array}$ & g Loss in \\
\hline
\end{tabular}

Student $t$ test.

In Our study, we found that Percentage of hearing loss was more in Group I workers than Group II workers.

\begin{tabular}{|c|c|c|c|}
\hline Hearing Loss & Group I & Group II & Total \\
\hline 0 & $46(46 \%)$ & $80(80 \%)$ & $126(63 \%)$ \\
\hline $1-20$ & $43(42 \%)$ & $7(7 \%)$ & $50(25 \%)$ \\
\hline $21-40$ & $11(11 \%)$ & $12(12 \%)$ & $23(11.5 \%)$ \\
\hline$>40$ & $0(0 \%)$ & $1(1 \%)$ & $1(0.5 \%)$ \\
\hline Total & $\mathbf{1 0 0 ( 1 0 0 \% )}$ & $\mathbf{1 0 0 ( 1 0 0 \% )}$ & $\mathbf{2 0 0 ( 1 0 0 \% )}$ \\
\hline Mean \pm SD & $6.96 \pm 8.16$ & $4.96 \pm 11.59$ & $5.96 \pm 10.05$ \\
\hline
\end{tabular}

$\mathrm{P}=0.160$, Not significant, student $\mathrm{t}$ test.

\begin{tabular}{|c|c|c|c|}
\hline Noise Level & Group I & Group II & Total \\
\hline 75 & $0(0 \%)$ & $100(100 \%)$ & $100(50 \%)$ \\
\hline 85 & $100(100 \%)$ & $0(0 \%)$ & $100(50 \%)$ \\
\hline Total & $\mathbf{1 0 0 ( 1 0 0 \% )}$ & $\mathbf{1 0 0 ( 1 0 0 \% )}$ & $\mathbf{2 0 0}(\mathbf{1 0 0} \%)$ \\
\hline Table 12. Noise Level Distribution in Two Groups of \\
Patients Studied \\
\hline
\end{tabular}

$\mathrm{P}<0.001^{* *}$, significant, Chi-Square test.

In Our study, we found that Group I workers were exposed to $85 \mathrm{~dB}$ of Noise. Group II workers were exposed to $75 \mathrm{~dB}$ of Noise.

\begin{tabular}{|c|c|c|c|}
\hline Type of Noise & Group I & Group II & Total \\
\hline Continuous & $100(100 \%)$ & $0(0 \%)$ & $100(50 \%)$ \\
\hline Intermittent & $0(0 \%)$ & $100(100 \%)$ & $100(50 \%)$ \\
\hline Total & $100(100 \%)$ & $100(100 \%)$ & $200(100 \%)$ \\
\hline Table 13. Type of Noise in Two Groups of Patients Studied \\
\hline
\end{tabular}

$\mathrm{P}<0.001^{* *}$, significant, Chi-Square test.

In Our study, we found that Group I workers were exposed to Continuous Noise. Group II workers were exposed to Intermittent Noise.

\section{DISCUSSION}

In our present study an attempt was made to study the relation between Noise and Hearing loss. Of 200 industrial workers, 74 had Noise induced hearing loss.

\section{Gender}

In our study most of the workers with NIHL were males in both Group I and Group II. Males can also be more commonly affected as they have health affecting habits like smoking compared to females.

\section{Duration of Employment}

In our study most of the workers with NIHL had the experience of 4 yrs.

\section{Pure Tone Audiometry}

In our study, maximum workers had PTA between $26-50 \mathrm{~dB}$ hl

According to WHO, the Severity of Deafness was classified as-

a. Mild deafness: $26-40 \mathrm{~dB}$,

b. Moderate deafness: $41-55 \mathrm{~dB}$ and

c. Moderately severe deafness: $56-70 \mathrm{~dB}$, based on mean hearing of speech frequencies.

According to Clarke et al Criteria for the classification of Hearing loss is as follows-

- Degree of hearing loss Hearing loss range (dB)

- $\quad$ Normal $<25$.

- $\quad$ Mild 26-40. 
- $\quad$ Moderate 41-55.

- $\quad$ Moderately severe 56-70.
- $\quad$ Severe 71-90.

- $\quad$ Profound 91+

\begin{tabular}{|c|l|l|l|}
\hline Category & \multicolumn{1}{|c|}{ Type of Impairment } & \multicolumn{1}{|c|}{ dB Level } & \multicolumn{1}{|c|}{ Percentage (\%) of Impairment } \\
\hline I & Mild hearing Impairment & $26-40 \mathrm{dBHL}$ in better ear & Less than $40 \%$ \\
\hline II a) & Moderate hearing Impairment & $41-60 \mathrm{dBHL}$ in better ear & $40 \%$ to $50 \%$ \\
\hline II b) & Severe hearing Impairment & $61-70 \mathrm{~dB}$ in better & $71 \%$ to $100 \%$ \\
\hline \multirow{2}{*}{ III } & a) Profound hearing Impairment & 71 to $90 \mathrm{~dB}$ & \multirow{2}{*}{$100 \%$} \\
\cline { 2 - 3 } & c) Total deafness & $91 \mathrm{~dB}$ and above in better ear & \\
\hline \multicolumn{2}{|c|}{ Table 14 } \\
\hline
\end{tabular}

In our study, Right ear is more affected than the Left ear.

This is comparable to study among operating engineers by Rop et al and Oi Saeng Hong who also show left sided predominance.

Nagaris et al also showed approximately half had bilaterally symmetric NIHL and $34.2 \%$ had left side predominance.

The probable reason for asymmetrical hearing loss in our study could be because of the position of the subjects, while working on the machine as right-handed person's right ear is closer to the machine.

\section{CONCLUSION}

A significant association was observed between the hearing loss and duration of exposure in both the ears among workers exposed to $85 \mathrm{~dB}$ of noise in Group 1 and $75 \mathrm{~dB}$ of noise in Group 2.

Regarding the pattern of hearing protector use, there were many assumptions and limitations.

However, after completion of the study, the following measures were recommended to enhance activities giving more emphasis on preventive, promotional and rehabilitative health care facilities. Before putting up any employee in any industry with high noise area, pre-placement \& periodic medical examination is vital. Monitoring of working environment, record keeping, health education to motivate the employees to use personal protective equipment and rehabilitation of the affected employees are essential. Research is needed regarding monitoring of the noise, source of noise, corrective measures and adverse effects of noise on health, workers' beliefs, attitudes and intentions regarding hearing loss prevention and training programme with an ultimate goal of good hearing. This will go a long way to prevent hearing impairment as an important occupational hazard.

\section{LIMITATIONS}

This cross-sectional study might overestimate the prevalence of occupational deafness. As adequate sample size could not be ensured, the results of this study could not be generalized but comparable with similar types of studies only.

\section{REFERENCES}

[1] Guthrie WKC. A history of Greek philosophy. The earlier Presocratics and the Pythagoreans. Vol. 1. UK: Cambridge University Press 1978: p. 1-175.
[2] Clavelin M. The natural philosophy of Galileo. USA: MIT Press 1974: p. 1-148.

[3] Slepecky NB. Structure of the mamalian cochlea. In: Dallos P, Popper AN, Fay RR, eds. The Cochlea. USA: Springer-Verlag 1996: p. 44-129.

[4] Bekesy GV. Zur Theorie des Hörens in die Schwingungsform der Basilarmembran. Phys Zeits 1928;29:793-810.

[5] Bekesy GV. Cochlear mechanics in experiments in the hearing. Part 4. New York, USA: McGraw-Hill 1960: p. 403-703.

[6] Nelson DI, Nelson RY, Concha-Barrientos M, et al. The global burden of occupational noise-induced hearing loss. Am J Ind Med 2005;48(6):446-58.

[7] Report of informal consultation on prevention of noise induced hearing loss held on 28-30 October 1997. Geneva: WHO.

[8] National Institute of Health. Consensus conference. Noise and hearing loss. JAMA 1990;263(23):3185-90.

[9] Dobie RA. Prevention of noise induced hearing loss. Arch Otolaryngol Head Neck Surg 1995;121(4):385-91.

[10] Raja S, Ganguly G. Impact of exposure to noise on the hearing acuity of employees in a heavy engineering industry. Indian J Med Res 1983;78:100-13.

[11] Bhattacharya SK, Saiyed HN, Roy A, et al. Hearing acuity in weavers of a textile mill. Indian J Med Res 1981;74:779-85.

[12] Bhattacharya SK, Tripathi SR, Kashyap S. Heat and noise problems in a drug and pharmaceutical firm in India. Indian Health 1990;28:203-7.

[13] Kumar A, Mathur NN, Varghese M, et al. Effect of tractor driving on hearing loss in farmers in India. Am J Ind Med 2005;47(4):341-8.

[14] Reilly MJ, Rosenman KD, Kalinowski DJ. MSN study on occupational noise-induced hearing loss surveillance in Michigan. Journal of Occupational \& Environmental Medicine 1998;40(8):667-74.

[15] McBride DI, Willims S. Institute of Occupational Health, University of Birmingham, UK, New Zealand. Occupational and Environmental Health Research Centre, University of Otago, Department of Preventive and Social Medicine, PO Box 913, Dunedin, New Zealand. gandalf.otago.ac.nz. 